\title{
ESTUDO ANATÔMICO DO LENHO DE STACHYTARPHETA GLABRA CHAM. (VERBENACEAE) $^{1}$
}

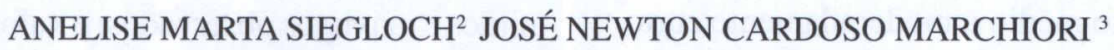 \\ SIDINEI RODRIGUES DOS SANTOS ${ }^{4}$
}

\section{RESUMO}

É anatomicamente descrito e ilustrado com fotomicrografias o lenho de Stachytarpheta glabra Cham., de acordo com IAWA Committee. A madeira apresenta: porosidade semi-difusa; poros em múltiplos radiais; elementos vasculares de comprimento médio, com apêndices; placas de perfuração simples e escalariformes; pontoações intervasculares pequenas, alternas e ornamentadas; parênquima paratraqueal-escasso; raios heterogêneos; e fibras libriformes curtas.

Palavras-chave: Anatomia da madeira, Stachytarpheta glabra, Verbenaceae.

\section{ABSTRACT}

[Wood anatomy of Stachytarpheta glabra Cham. (Verbenaceae)].

The wood anatomy of Stachytarpheta glabra Cham. is described and illustrated with photomicrographs, according to IAWA Committee. The wood structure presents: semi-diffuse porous wood; radial multiple pores; medium length vascular elements, with appendices; simple and scalariform perforation plates; small alternate vestured pits; scanty paratracheal parenchyma; heterogeneous rays; and short libriform fibers.

\section{INTRODUÇÃO}

De distribuição pantropical e, principalmente, neotropical, a família Verbenaceae inclui cerca de 36 gêneros e 1000 espécies (Souza \& Lorenzi, 2012) de ervas, lianas, arbustos e árvores, de caules geralmente quadrangulares, providos, por vezes, com acúleos ou espinhos (Judd et al., 2009).

Composto de 133 espécies, aproximadamente, geralmente de ambientes úmidos e sombreados (Santos et al., 2009), o gênero Stachytarpheta, é quase todo americano, havendo uma

1 Recebido para publicação em 20/06/2013 e aceito para publicação em 20/09/2013.

2 Mestranda do Curso de Pós-Graduação em Engenharia Florestal. Bolsista - CAPES. Universidade Federal de Santa Maria, CEP 97105-900. Santa Maria, RS, Brasil. anesiegloch@yahoo.com.br

3 Engenheiro Florestal, Dr. Bolsista de Produtividade em Pesquisa (CNPq - Brasil). Professor Titular do Departamento de Ciências Florestais, Universidade Federal de Santa Maria. Santa Maria, RS, Brasil.

${ }^{4}$ Biólogo, Dr. Núcleo de Estudos Botânicos Balduino Rambo, UFSM. única espécie do Velho Mundo. O Brasil, com 79 espécies, constitui o centro de diversidade do gênero (Atkins 2005).

Arbusto ramificado de até $2 \mathrm{~m}$ de altura, Stachyrtapheta glabra Cham. forma populações em campos ferruginosos e rupestres com afloramentos quartzíticos, em altitudes superiores a 1000m (Salimena-Pires \& Giulietti, 1998). Planta valiosa para a fauna, é visitada especialmente por beija-flores e insetos, devido ao néctar produzido (Vincent et al., 2002).

Com relação à anatomia do lenho, Metcalfe \& Chalk (1972) relacionam os seguintes caracteres para as Verbenaceae: vasos de diâmetro médio, em padrão radial, oblíquo ou tangencial; porosidade comumente em anel; elementos vasculares de comprimento médio a muito curto; placas de perfuração simples, embora escalariformes e/ou reticuladas em alguns gêneros; pontoações intervasculares diminutas a moderadamente grandes; pontoações raiovasculares semelhantes, em sua maioria; parênquima paratraqueal estreito-vasicêntrico, por vezes abundante e confluente; raios hete- 
rogêneos a homogêneos, com 3-4 células de largura, por vezes muito largos; e fibras com pontoações simples, geralmente septadas, de comprimento médio a moderadamente curto.

Para a família, a literatura cita a ocorrência de placas de perfuração simples, menos comumente escalariformes, reticuladas ou combinação de placas simples e escalariformes (Record \& Hess, 1949; Metcalfe \& Chalk, 1972; Meylan \& Butterfield, 1975).

O presente estudo visa a descrição do lenho de Stachytarpheta glabra e identificar caracteres de valor taxonômico para o gênero envolvido.

\section{MATERIAL E MÉTODOS}

O material em estudo, coletado por Gert Hatschbach em Minas Gerais, consiste de uma amostra de madeira e respectiva exsicata, conservados no Museu Botânico Municipal de Curitiba (MBM) com o número 40.835 .

Para a confecção das lâminas histológicas foram extraídos três corpos de prova $(1 \times 2 \times 3 \mathrm{~cm})$ da parte mais externa do lenho, próxima ao câmbio, orientados para a obtenção de cortes nos planos transversal, longitudinal radial e longitudinal tangencial. Outro bloquinho foi também retirado, com vistas à maceração.

A confecção das lâminas histológicas seguiu a metodologia descrita em Burger \& Richter (1991). Paras as lâminas de macerado seguiuse o método de Jeffrey (Freund, 1970). Os cortes anatômicos foram tingidos com acridinavermelha, crisoidina e azul-de-astra (Dujardin, 1964); o macerado, apenas com safranina (1\%). Na montagem das lâminas permanentes usouse Entellan.

As descrições basearam-se nas recomendações do IAWA Committee (Wheeler et al., 1989). No caso da percentagem dos tecidos foram realizadas 600 determinações ao acaso, com auxílio de contador de células, conforme proposto por Marchiori (1980). A abundância de poros foi obtida a partir de um quadrado de área conhecida, superposto a fotomicrografias de seções transversais da madeira.

As medições foram realizadas em microscópio Carl Zeiss, no Laboratório de Anatomia da
Madeira da Universidade Federal de Santa Maria. Nas características quantitativas, os números entre parênteses equivalem aos valores mínimos e máximos observados; o valor que acompanha a média é o desvio padrão. As fotomicrografias foram tomadas em microscópio Olympus CX40, equipado com câmera digital Olympus Camedia c3000, no Laboratório de Anatomia da Madeira da Universidade Federal do Paraná.

\section{DESCRIÇÃO ANATÔMICA}

Anéis de crescimento: distintos, evidenciados por poros pequenos no lenho tardio e maiores no lenho inicial, bem como pela diferença na espessura da parede de fibras (Figura 1 A,B).

Vasos: extremamente numerosos $(108 \pm 52$ $(50-200)$ poros $\left./ \mathrm{mm}^{2}\right)$, ocupando $21 \pm 4,5 \%$ do volume da madeira. Porosidade semi-difusa. Poros em múltiplos radiais de 2 a 9 , bem como solitários e racemiformes, de seção circular ou oval $(51 \pm 18,3(20-88) \mu \mathrm{m})$ e paredes finas $(3,5 \pm 0,8(2,5-5) \mu \mathrm{m}$ (Figura 1 A,B). Elementos vasculares de $394 \pm 84(250-600) \mu \mathrm{m}$ de comprimento, com apêndices geralmente em uma extremidade $(20-110 \mu \mathrm{m})$. Placas de perfuração simples, por vezes escalariformes, oblíquas até transversais (Figura 1 D,F). Pontoações intervasculares pequenas, circulares $(5,8 \pm 0,5$ $(5,2-6,2) \mu \mathrm{m})$, alternas, com abertura em fenda elíptica, inclusa, ornamentada. Pontoações raio-vasculares semelhantes às intervasculares, porém menores $(4,4 \pm 0,5(4-5,2) \mu \mathrm{m})$ (Figura $1 \mathrm{C}, \mathrm{D})$. Espessamentos espiralados e conteúdos, ausentes.

Parênquima axial: paratraqueal-escasso, representando $3 \pm 1,3 \%$ do volume da madeira (Figura $1 \mathrm{~A}, \mathrm{~B}$ ). Séries parenquimáticas de 278 $\pm 42(213-363) \mu \mathrm{m}$ de altura, compostas de 2 -4 células (Figura 1E).

Raios: numerosos $(9 \pm 1,3(7-11)$ raios/ $\mathrm{mm})$, heterogêneos, com $1-3$ (4) células de largura, ocupando $17 \pm 2,7 \%$ do volume da madeira (Figura 1 E,F). Os unisseriados, de 210 $\pm 83(100-400) \mu \mathrm{m}$ e $2-13$ células de altura. Os multisseriados, de $465 \pm 113(200-700)$ 

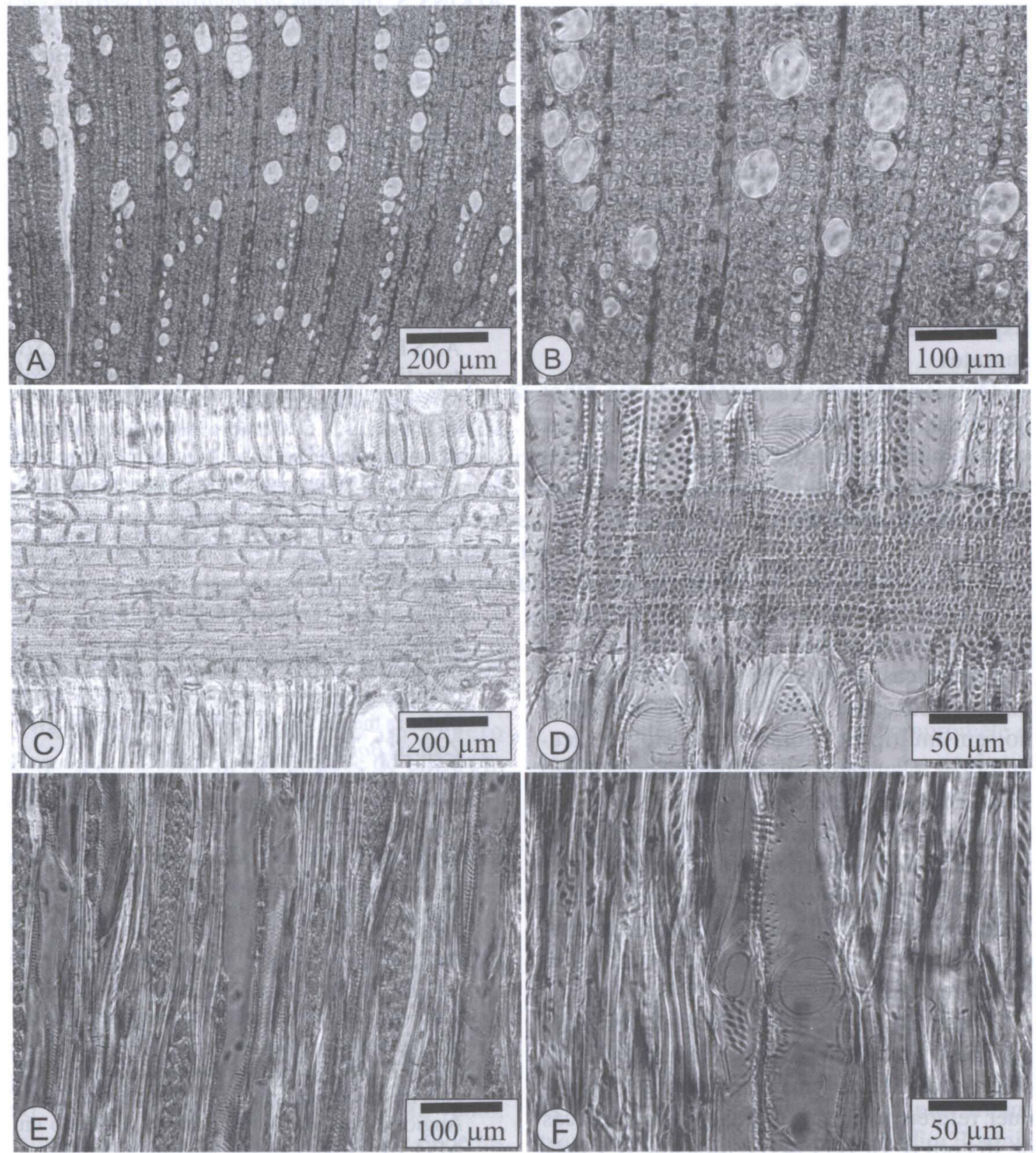

FIGURA 1 - Aspectos anatômicos do lenho de Stachytarpheta glabra Cham. A - Porosidade semi-difusa, com poros solitários e em múltiplos radiais, e limite do anel de crescimento (seção transversal). B - Limite do anel de crescimento, com poros maiores no inicio do anel (seção transversal). C - Raio heterogêneo, com células procumbentes no corpo central, e células eretas e quadradas, nas margens (seção longitudinal radial). D - Células procumbentes de raio com pontoações raio-vasculares e placas de perfurações escalariformes (seção longitudinal radial). E-Raios multisseriados (seção longitudinal tangencial). F - Fibras libriformes e vasos com placas de perfuração simples e escalariformes (seção longitudinal tangencial). 
$\mu \mathrm{m}$ e 8 - 40 células de altura, compostos de células procumbentes no corpo central e $1-4$ fileiras marginais de células quadradas e/ou eretas. Raios fusionados, pouco frequentes. Células perfuradas, presentes. Conteúdos especiais, células radiais de paredes disjuntas, raios agregados, cristais e células envolventes, ausentes.

Fibras: libriformes, curtas $(878 \pm 142(830$ - 1370) $\mu \mathrm{m})$, de $22 \pm 3,4(15-30) \mu \mathrm{m}$ de largura e paredes espessas $(7,6 \pm 1,9(5-13) \mu \mathrm{m})$, ocupando $59 \pm 2,9 \%$ do volume da madeira (Figura 1 A,B ). Fibras gelatinosas, presentes. Espessamentos espiralados e traqueóides, ausentes.

Outros caracteres: variantes cambiais, tubos laticíferos e taniníferos, canais intercelulares, células oleíferas, inclusões minerais, células mucilaginosas e estratificação, ausentes. Máculas medulares, presentes.

\section{ANÁLISE DA ESTRUTURA ANATÔMICA}

A estrutura microscópica do lenho de Stachytarpheta glabra Cham. corresponde às características, referidas na literatura para a família Verbenaceae: vasos de diâmetro pequeno, em múltiplos radiais, solitários e racemiformes; elementos vasculares de comprimento médio, com apêndices; placas de perfuração simples e escalariformes; pontoações intervasculares de diâmetro médio, alternas e ornamentadas; pontoações raio-vasculares semelhantes às intervasculares; parênquima paratraqueal-escasso; raios heterogêneos; e fibras libriformes (Metcalfe \& Chalk, 1972).

Apesar do grande número de espécies, o gênero Stachytarpheta foi pouco investigado sob o ponto de vista anatômico, não constando qualquer referência ao mesmo nas obras clássicas de Record \& Hess (1949) e Metcalfe \& Chalk (1972).

À semelhança de outras espécies da família, observou-se mais de um tipo de placa de perfuração em vasos (simples e escalariforme), concordando, neste aspecto, com referências de Record \& Hess (1949), Metcalfe \& Chalk(1972) e Meylan \& Butterfield (1975).

\section{REFERÊNCIAS BIBLIOGRÁFICAS}

ATKINS, S. The genus Stachytarpheta (Verbenaceae) in Brazil. Kew Bulletin, n. 60, p 161-272, 2005.

BURGER, L.M.; RICHTER, H.G. Anatomia da Madeira. São Paulo: Ed. Nobel, 1991. 154 p.

DUJARDIN, E.P. Eine neue Holz-Zellulosenfaerbung. Mikrokosmos, n. 53, p. 94, 1964.

FREUND, H. Handbuch der Mikroskopie in der Technik. Frankfurt: Umsham Verlag, 1970.375 p.

GOTTWALD, H.; PARAMESWARAM, N. Vielfache Gefassdurchbrechungen in der Familie Dipterocarpaceae. Zaitschr. F. Bot., n. 52, p. 321334, 1964.

JUDD, W. S.; CAMPBELL, C. S.; KELLOGG, E. A.; STEVENS, P. F.; DONOGHUE, M. J. Sistemática vegetal: um enfoque filogenético. Porto Alegre: Artmed, 2009. p. 490-492.

MARCHIORI, J.N.C. Comprovação da viabilidade da utilização da secção longitudinal tangencial para a determinação histométrica dos elementos axiais do xilema secundário. In: Anais do IV Congresso Florestal Estadual, Nova Prata, RS, p. $180-184,1980$.

METCALFE, C.R.; CHALK, L. Anatomy of the Dicotyledons. Oxford: Clarendon Press, 1972. p. 1030-1041.

MEYLAN, B. A.; BUTTERFIELD, B. G. Occurrence of simple, multiple and combination perforation plates in the vessels of New Zealand woods. New Zeal. J. Bot., n. 13, p. 1-18, 1975.

RECORD, S. J.; HESS, R. W. Timbers of the New World. New Haven: Yale University Press, 1949. p. 436-443.

SALIMENA-PIRES, F.R.; GIULIETTI, A.M. Flora da Serra do Cipó, Minas Gerais: Verbenaceae. Bolet. Bot. Univ. São Paulo, v. 17, p. 155-186, 1998.

SANTOS, S. S.; MELO, J. I. M.; ABREU, M. C.; SALES M. F. Verbenaceae sensu stricto na região de Xingó: Alagoas e Sergipe, Brasil. Rodriguésia, v. 60, n. 4, p. 985-998, 2009.

SOUZA, V.C.; LORENZI, H. Botânica Sistemática: guia ilustrado para identificação das famílias de Angiospermas da flora brasileira, baseado em APG III. Nova Odessa: Instituto Plantarum, 2012. p. 674-678.

WHEELER, E.A.; BAAS, P.; GASSON, P.E. IAWA list of microscopic features for hardwood identification. IAWA Bulletin, v.10, n. 3, p. 218359, 1989.

VINCENT, C. R.; JACOBI, C. M.; ANTONINI, Y. Diversidade na adversidade. Ciência Hoje, v. 31, p. 64-67. 2002. 